\title{
Sistem Sterilisator Otomatis Berbasis Arduino Uno
}

\author{
M. Aditya1, Dwiprima Elvanny Myori² \\ 1,2Universitas Negeri Padang \\ Jl. Prof Dr. Hamka Air Tawar, Padang, Indonesia \\ m.aditya2703@gmail.com ${ }^{1}$,elvannymyori@gmail.com ${ }^{2}$
}

\begin{abstract}
Sterilization is a process of killing all life forms of microorganisms present in samples, tools or a certain environment. The problem that is often faced by medical personnel to sterilize equipment is the aspect of time effectiveness. In designing this final project, the aim is to create an Arduino Uno based Automatic Sterilizer System tool which is a tool for sterilizing reusable medical devices with a more accurate time and temperature. This Arduino Uno-based Automatic Sterilizer system tool can be set at the desired time and temperature so that it is more efficient to use for medical personnel. By using a Thermocouple as a temperature sensor and the measured temperature will be displayed on the Liquid Crystal Display (LCD). For control systems using the Arduino Uno for data processing. The way this tool works is to adjust how much time and temperature you want then press the start button, then the heater will work automatically until the desired temperature is reached and after the time and temperature have been reached, the buzzer will activate indicating the sterilization process has been completed. From the research results, it is concluded that the sterilization process takes 10 minutes to reach a temperature of 1200C. From the results of the analysis, this tool is classified as better than the previous tool which took 30-60 minutes to reach a temperature of $100^{\circ} \mathrm{C}$.
\end{abstract}

Keywords: Sterilization, Wet Sterilizer, Arduino Uno, Thermocouple, LCD.

Abstrak - Sterilisasi adalah suatu proses membunuh segala bentuk kehidupan mikroorganisme yang ada pada sample, alatalat atau lingkungan tertentu Secara teknis. Permasalahan yang sering dihadapi oleh tenaga medis untuk mensterilkan alat adalah segi keefektifan waktu. Dalam perancangan tugas akhir ini bertujuan untuk menciptakan sebuah alat Sistem Sterilisator Otomatis berbasis Arduino Uno yang menjadi alat untuk mensterilkan peralatan medis yang sifatnya bisa dipakai ulang dengan waktu dan suhu yang lebih akurat. Alat Sistem Sterilisator Otomatis berbasis Arduino Uno ini dapat diatus berapa waktu dan suhu yang diiinginkan sehingga lebih efisien untuk digunakan bagi para tenaga medis. Dengan menggunakan Thermocouple sebagai sensor suhu dan besaran suhu yang terukur akan ditampilkan pada Liquid Crystal Display (LCD). Untuk sistem kontrol menggunakan Arduino Uno untuk pemprosesan data. Cara kerja alat ini adalah dengan mengatur berapa waktu dan suhu yang diinginkan kemudian teakan tombol start, selanjutnya heater akan bekerja secara otomatis sampai suhu yang diinginkan tercapai dan setelah waktu dan suhu telah tercapai maka buzzer akan aktif menandakan proses sterilisasi telah selesai. Dari hasil penelitian menyimpulkan, proses sterilisasi membutuhkan waktu 10 menit untuk mencapai suhu $120^{\circ} \mathrm{C}$, dari hasil analisa alat ini tergolong lebih baik dibandingkan dengan alat yang sebelumnya yang membutuhkan waktu 30 - 60 menit untuk mencapai suhu $100^{\circ} \mathrm{C}$.

Kata Kunci: Sterilisasi, Sterilisator basah, Arduino Uno, Thermocouple, LCD

\section{Pendahuluan}

Kemajuan teknologi yang berjalan begitu pesat menuntut manusia untuk mengikuti kemajuan di segala bidang. Tidak dapat dipungkiri masyarakat sebagai subjek sekaligus objek dari teknologi harus bisa mengikuti segala bentuk kemajuan tersebut. Peralatan kedokteran yang berbasis elektronika merupakan salah satu pendukung bagi para ahli medis dalam mendiagnosa dan memerangi penyakit yang umumnya disebabkan oleh virus, bakteri, kuman dan sebagainya [1]. Kuman dan bakteri yang merugikan tersebut dapat dimusnahkan dengan berbagai cara. Salah satunya dengan cara sterilisasi dengan menggunakan pemanasan air hingga mencapai suhu di atas $120^{\circ} \mathrm{C}$ dalam beberapa waktu tertentu secara otomatis, sterilisasi dilakukan pada instrumen pakai ulang pada peralatan medis seperti gunting, pisau bedah, dan pinset [2]. Salah satu alat yang memiliki teknologi yang cukup tinggi dan berbasis elektronika adalah Sterilisator basah.

Sterilisator basah merupakan alat pensterilisasi yang menggunakan uap air. Uap air tersebut didapat dari proses pemanasan air. Sterilisator basah tersebut dapat memusnahkan jasad renik atau mikroorganisme [3]. Sedangkan sterilisasi adalah pelepasan suatu material bahan ataupun alat dari berbagai mikroorganisme hidup atau stadium istirahatnya. Sel -sel vegetatif bakteri dan fungi dapat dimatikan pada suhu $60^{\circ} \mathrm{C}$ dan dalam waktu 5 -10 menit. Namun spora dapat mati pada suhu di atas $80{ }^{\circ} \mathrm{C}$ dan spora bakteri baru mati di atas suhu $110^{\circ} \mathrm{C}$ 
selama 10 menit [4]. Sterilisasi merupakan bagian integral dari pelayanan kesehatan dan pengendalian infeksi di rumah sakit. Upaya menghasilkan produk yang steril bertujuan untuk membantu meningkatkan kualitas pelayanan pasien dan mencegah dampak merugikan bagi pasien.

Sterilisator basah merupakan sebuat alat yang berfungsi untuk mensterilkan suatu peralatan medis dengan memanfaatkan metode perubahan energi listrik menjadi energi panas. Heater yang prinsip dasarnya berfungsi sebagai pemanas dan akan memanaskan air didalam wadah penampung hingga suhu yang diinginkan tecapai dalam waktu tertentu[5]. Sensor thermocouple merupakan sensor suhu untuk mendeteksi setiap perubahan suhu yang terjadi pada saat pemanasan yang dilakukan heater berlangsung[6]. Buzzer yang bekerja secara otomatis akan $O N$ pada saat suhu yang diinginkan dideteksi oleh sensor thermocouple telah tercapai. Heater, sensor thermocouple dan buzzer akan bekerja berdasarkan perintah yang dibuat pada Arduino Uno. Program akan dirancang pada software Intergrated Development Environtment (IDE) sehingga dapat mengendalikan seluruh input dan output yang digunakan pada sistem ini sesuai dengan yang diinginkan.

Berdasarkan beberapa penelitian sebelumnya, masih menggunakan cara-cara yang manual dan membutuhkan waktu sterilisasi yang terbilang cukup lama. Oleh karena itu penulis ingin mengembangkan sebuah sistem Sterilisasi Otomatis Berbasis Arduino Uno yang dapat mengatur waktu dan suhu yang diinginkan dengan menggunakan Arduino Uno sebagai pemprosesan.

\section{Arduino Uno}

“Arduino merupakan sebuah platform elektronik yang bersifat open source, berbasis pada software dan hardware yang fleksibel dan mudah digunakan. Nama Arduino tidak hanya dipakai untuk menamai board rangkaian saja, tetapi juga untuk menamai bahasa dan software pemrogramannya, serta IDE (Integrated Development Environment). Pada pembuatan tugas akhir ini penulis menggunakan Arduino Uno. Masing-masing dari 14 pin digital pada Arduino Uno dapat digunakan sebagai input atau output, menggunakan fungsi pin Mode(), digital Write(), dan digital Read() yang beroperasi di 5 volt. Setiap pin dapat memberikanatau menerima maksimum $40 \mathrm{~mA}$ dan memiliki resistor pull-up internal dari 20-50 K.

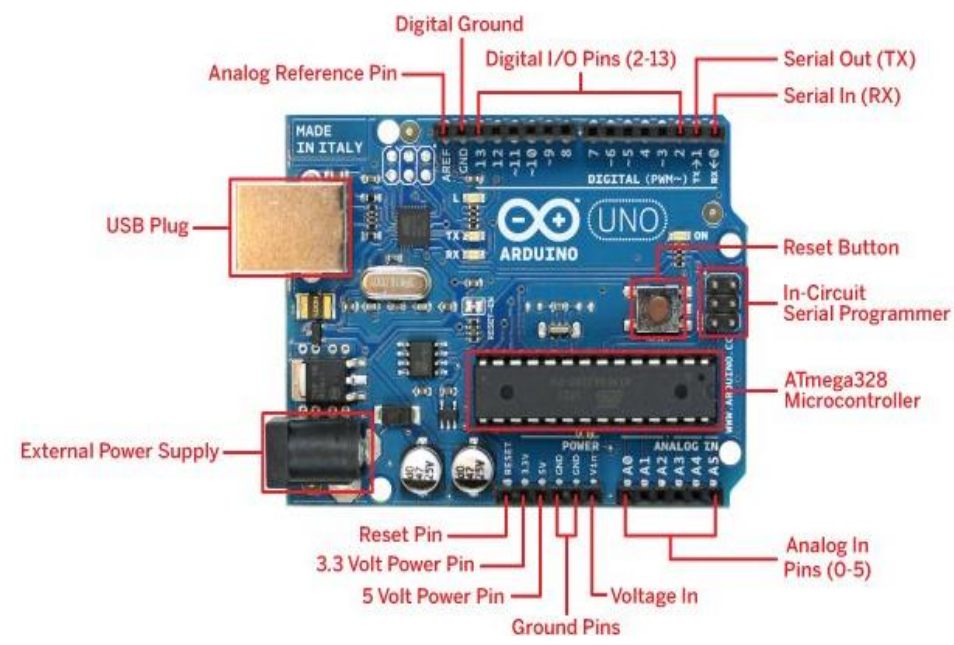

Gambar 1. Arduino Uno

\section{Switching Power Supply}

Switching power supply atau yang lebih dikenal dengan switched-mode-power-supply (SMPS), adalah catu daya elektronik yang terdiri dari sebuah regulasi switching yang disediakan sesuai kebutuhan pada tagangan keluaran. Sebuah SMPS adalah daya pengubah yang meneruskan daya dari sebuah sumber untuk beban yang ideal tanpa rugi-rugi. Fungsi dari pengubah adalah untuk menyediakan tegangan keluaran pada level yang berbeda dibandingkan tegangan masukan. Sebuah regulator linier mempertahankan tegangan keluaran yang dikehendaki dengan menghilangkan kelebihan daya pada rugi-rugi tahanan (misalnya, dalam sebuah resistor atau di daerah kolektor-emiter dari transistor dalam modus aktif). Sebuah regulator linier mengatur keluaran baik tegangan atau arus dengan menghilangkan kelebihan daya listrik dalam bentuk panas.

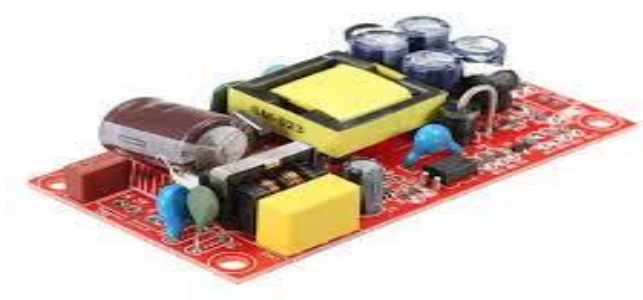

\section{Senor Suhu}

Gambar 2. Switching Power Supply

Termokopel (Thermocouple) adalah sebuah jenis sensor suhu yang digunakan untuk mendeteksi atau mengukur suhu melalui dua jenis logam konduktor berbeda yang digabung pada ujungnya sehingga menimbulkan efek Thermo-electric"."Efek Thermo-electric 
pada Termokopel ini ditemukan oleh seorang fisikawan Estonia bernama Thomas Johann Seebeck pada Tahun 1821, dimana sebuah logam konduktor yang diberi perbedaan panas secara gradient akan menghasilkan tegangan listrik. Perbedaan Tegangan listrik diantara dua persimpangan (junction) ini dinamakan dengan Efek "Seeback".

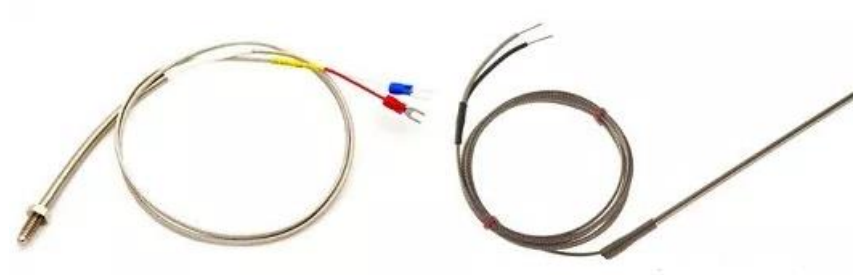

Gambar 3. Sensor Suhu.

\section{LCD}

LCD (Liquid Cristal Display) berfungsi sebagai penampil data baik dalam bentuk karakter, huruf, angka ataupun grafik.

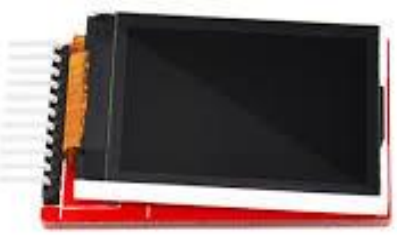

Gambar 4. LCD

\section{Teknik Pemograman}

1. Algoritma

Algoritma adalah urutan langkah yang logis untuk menyelesaikan masalah tertentu. Didalam anlisis masalah diperlukan tindakan untuk mengidentifikasi informasi yang menjadi keluaran pemecahan masalah dan data-data yang menjadi masukan. Berdasarkan hal itu diperlukan prosedur untuk mengolah masukan tersebut menjadi keluaran yang dikehendaki. Algoritma memiliki kriteria sebagai berikut :

a. Input

Dari sisi input, minimal program harus memiliki nol input atau lebih dari pengguna. Program pasti memiliki input. Yang dimaksud dengan memiliki nol input berarti program tidak mendapatkan masukan data dari pengguna secara langsung, namun semua data yang akan digunakan oleh program sudah dideklarasikan di dalam kode program yang akan dieksekusi. Jadi tidak perlu di inputkan dari luar. Sedangkan jika mendapatkan input dari pengguna, data bias dimasukan melalui tampilan program, misalnya melalui textbox, atupun melalui file/basis data yang terdapat di suatu tempat/ server tertentu.

b. Output

Dari sisi output, minimal program harus memiliki 1 buah output. Program pasti menghasilkan output karena program dibuat untuk tujuan tertentu yang disebut output. Output program bias ditampilkan ke layar (screen), ditulis ke file, atau disimpan di clipboard untuk kemudian dipakai di program lain atau disimpan dalam basis data.

c. Finite (Terbatas)

Program harus dan pasti berhenti, bukan tak terhingga. Suatu program yang dieksekusi haruslah berhenti dan selesai, bukan berjalan terus menerus hingga hang up atau not responding, sehinggan harus dimatikan secara paksa. Suatu program dapat mengalami infinite (tak pernah berhenti) karena kesalahan programmer, mungkin karena tidak teliti atau terjadi error yang tidak menentu.

d. Definite (Pasti)

Program harus jelas arah dan tujuannya. Suatu program harus jelas kapan mulai dan kapan berakhir, apa tujuannya, dan memiliki logika yang jelas agar dapat menghasilkan output yang sesuai dengan yang diinginkan.

e. Efisien

Artinya, program harus efisien, tidak memakan banyak memori, tidak melakukan halhal yang tidak dibutuhkan.

Bentuk-bentuk dasar algoritma sebagai berikut :

1. Algoritma sekuensial

Algoritma sekuensial merupakan alur pemikiran yang terstruktur, terurut, pasti, dan jelas untuk menyelesaikan masalah. Dalam algoritma ini kadang ada langkah-langkah yang tidak boleh ditukar urutannya. 
2. Algoritma percabangan

Algoritma percabangan adalah algoritma untuk memilih salah satu dari beberapa pilihan yang ada. Algoritma ini mengharuskan programmer memilih langkah yang harus dilakukan berdasarkan kondisi tertentu. Yang perlu diperhatikan pada algoritma ini adalah solusi dari pilihan akan dilakukan jika kondisinya terpenuhi, dalam arti kondisinya menghasilkan nilai benar (TRUE). Jika kondisi benar maka solusi akan dijalankan, dan jika salah maka tidak akan dijalankan.

3. Algoritma pengulangan

Algoritma perulangan berarti terdapat satu atau lebih kejadian/tindakan yang harus diulang terus-menerus sampai kondisinya tidak terpenuhi lagi.

\section{Metode}

Metode yang penulis gunakan dalam penelitian ini adalah membuat perangkat hardware sistem otomatisasi pada aquascape serta pelaksanaan percobaan pengujian pada masing-masing komponen.

\section{A. Perancangan Software}

\section{Blok Diagram}

Pada Tugas Akhir ini perancangan dari alat Sistem Sterilisator Otomatis Berbasis Arduino Uno terdiri dari beberapa bagian, yaitu: Arduino Uno, LCD, Relay, Heater, Sensor suhu, Power Supply, Buzzer dan setting timer. Berikut blok diagram keseluruhan seperti dibawah ini.

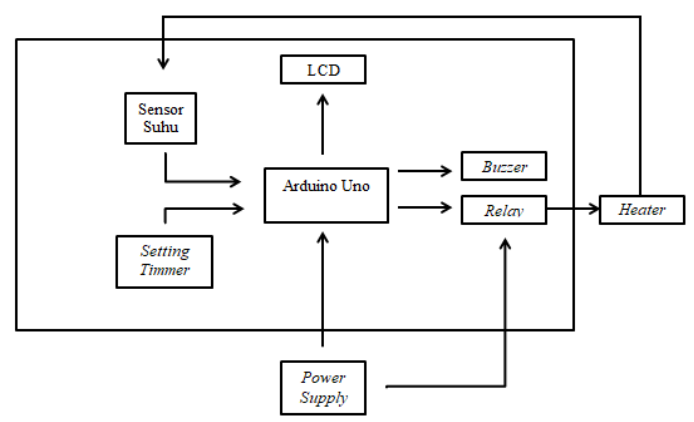

Gambar 5. Blok diagram Keseluruhan

Berdasarkan blok diagram keseluruhan sistem di atas fungsi dari masing-masing blok diagram sebagai berikut:

\section{Arduino Uno}

Arduino Uno merupakan bagian yang berfungsi untuk memproses input yang dimasukkan dan menghasilkan output berupa suhu.

\section{Heater}

Heatar merupakan rangkaian kontrol suhu dirancang untuk mengontrol kerja dari elemen pemanas dan membuat suhu ruang agar tetap stabil sehingga tidak terjadi penurunan saat sudah terjadi proses sterilisasi atau waktu sudah menghitung mundur.

3. Setting timer

Setting timer merupakan rangkaian kontrol timer berfungsi untuk memberikan pulsa clock pada rangkaian setting waktu sterilisasi agar pada saat suhu tercapai waktu dapat menghitung mundur. Rangkaian ini digunakan untuk mengatur nilai waktu sterilisasi.

4. Sensor suhu

Sensor suhu merupakan sensor digunakan untuk mengukur suhu pada saat berlangsungnya proses sterilisasi.

5. LCD (Liquid Crystal Digital)

LCD merupakan media tampilan yang digunakan untuk menampilkan berapa lama waktu sterilisasi dan untuk menampilkan besarnya suhu yang telah tercapai.

6. Power Supply

Power Supply merupakan komponen pemberi suatu tegangan serta arus listrik kepada komponen komponen lainnya yang telah terpasang dengan baik pada motherboard, yang bertujuan agar perangkat atau komponen - komponen lainnya bisa berfungsi sebagaimana mestinya sesuai dengan tugasnya.

\section{Buzzer}

Buzzer merupakan sebuah komponen elektronika yang dapat mengubah sinyal listrik menjadi getaran suara pada saat proses sterilisasi telah selesai.

8. Relay

Relay merupakan prinsip elektromagnetik untuk menggerakkan kontak saklar sehingga dengan arus listrik yang kecil (low power) dapat menghantarkan listrik yang bertegangan lebih tinggi menuju heater. 


\section{Flowchart sistem}

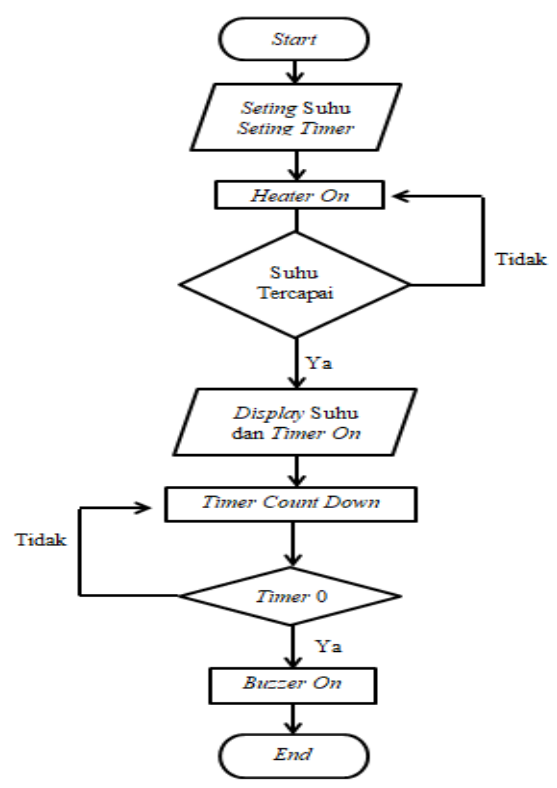

Gambar 6 . Flowcart sistem keseluruhan

Pada gambar 2 diatas merupakan flowchart atau diagram alur cara kerja alat secara keseluruhan, sistem diawal dengan mengaktifkan alat dan aktifasi alat akan mengaktifkan sistem setting waktu dan suhu kemudian dari sistem setting waktu dan suhu terbaca tersebut kemudian akan diproses oleh Arduino Uno dan mengaktifkan heater kemudian aktifasi heater akan mendapatkan output berupa suhu yang tercapai dan kemudian akan mengaktifkan display suhu dan timer akan ON selanjutnya timer count down dan akan menghitung mundur waktu dan setelah waktu 00 maka akan mengaktifkan Buzzer. Sistem akan berjalan secara kontiniu sampai kondisi alat dimatikan.

\section{B. Perancangan Mekanik (hardware)}

Perancangan hardware merupkan hal yang begitu penting dalam pembuatan tugas akhir ini. Karena dengan adanya hardware maka sistem dapat diuji secara nyata apakah alat ini dapat bekerja dengan baik atau tidak. Bentuk hardware yang dirancang merupakan box yang didalamnya tedapat rangkaian yang dibuat untuk mengendalikan alat Sistem Sterilisator Otomatis berbasis Arduino Uno. Rancangan alat seperti gambar berikut.

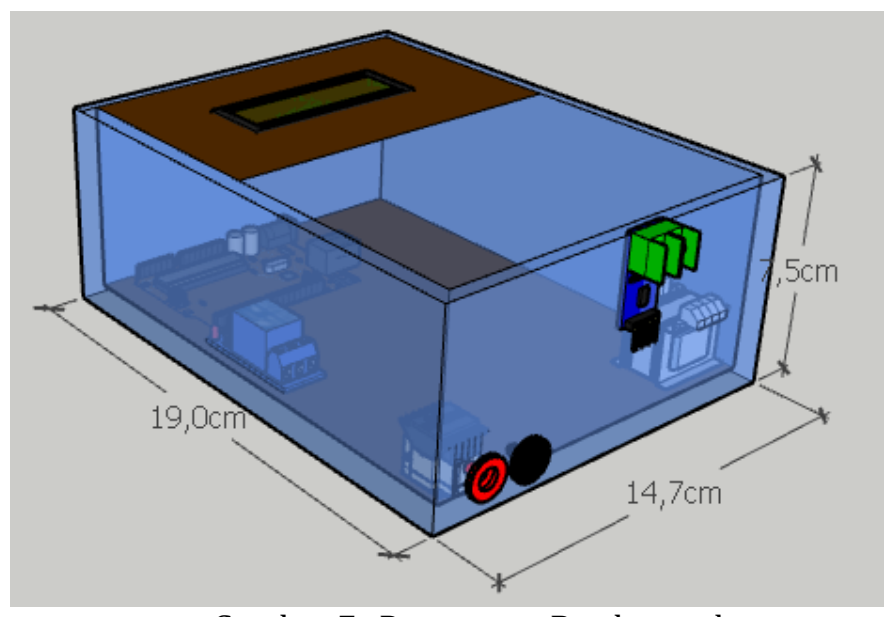

Gambar 7. Rancangan Box kontroler

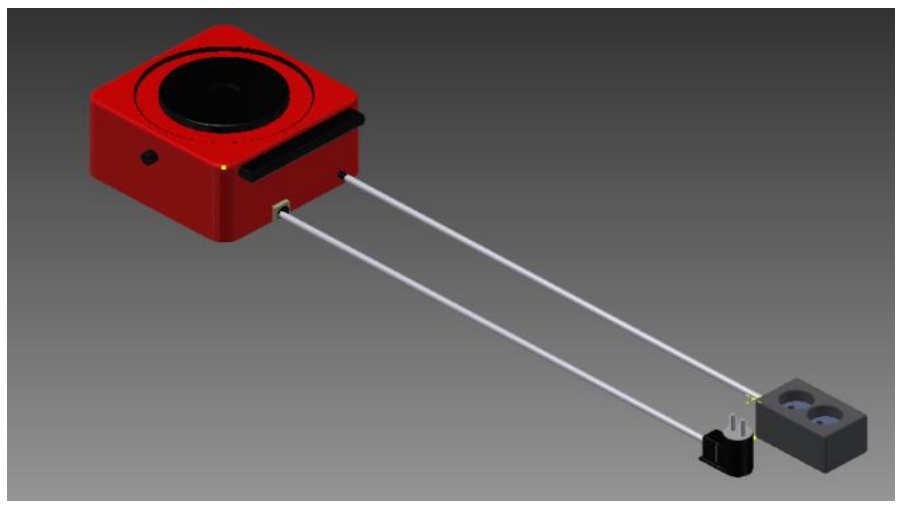

Gambar 8. Rancangan Heater

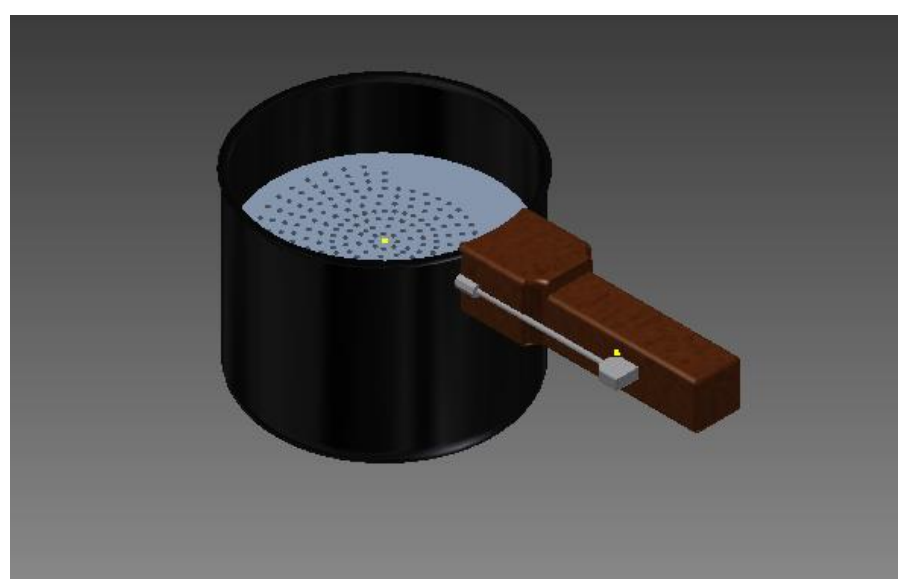

Gambar 9. Rancangan Heater

\section{Perancangan Software}

Perancangan software secara keseluruhan pada tugas akhir ini menggunakan Arduino IDE (Integrated Development Environment), yaitu software yang merupakan bawaan dari arduino itu sendiri, sehingga dapat mengendalikan seluruh input dan output yang 
digunakan pada alat sistem Sterilisator Otomatis Berbasis Arduino Uno. Pada software Arduino IDE dapat dilakukan proses compile dan upload program yang dibuat ke dalam mikrokontroler arduino. Kode kode program arduino dibuat menggunakan bahasa pemrograman C. Untuk komunikasi antara perangkat dengan pengguna, penulis menggunakan tombol yang berfungsi untuk memberikan input untuk mengatur waktu dan suhu, serta hasil dari pengaturan akan ditampilkan melalui LCD.

\section{Perancangan Rangkain Elektronik Keseluruhan}

Perancangan rangkaian elektronika secara keseluruhan pada tugas akhir ini terdapat semua komponen yang digunakan yaitu, input tegangan kemudian Arduino Uno yang berfungsi sebagai kendali utama seluruh komponen. Sensor thermocouple, sebagai input yang mendeteksi besaran suhu pada saat kondisi ON. LCD sebagai output yang akan menampilkan data dari pembacaan waktu dan sensor. Gambar dibawah ini merupakan perancangan rangkaian elektronika keseluruhan.

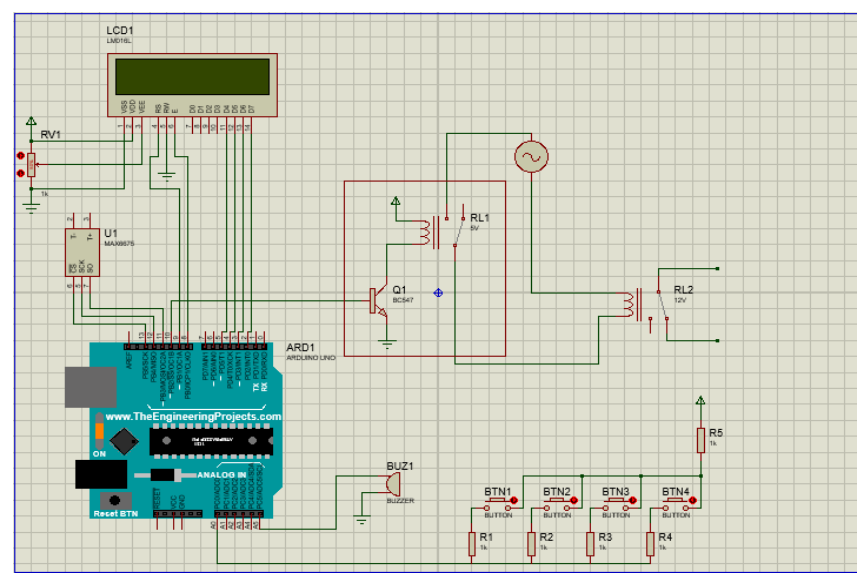

Gambar 10. Rangkaian elektronik keseluruhan

\section{HASIL DAN PEMBAHASAN}

Pengujian Pada bagian ini dilakukan beberapa pegujian dan analisa pada seluruh bagian input dan output. Pengujian dan analisa sensor dilakukan untuk mengetahui sensor yang digunakan berfungsi dengan baik atau tidak sebagai input sesuai dengan yang dikehendaki. Pada pengujian alat ini adalah dimulai dengan mengoperasikan alat Sistem Sterilisator Otomatis Berbasis Arduino Uno dilanjutkan dengan pengambilan data dari alat ini. Gambar 7 berikut ini merupakan bentuk alat keseluruhan.

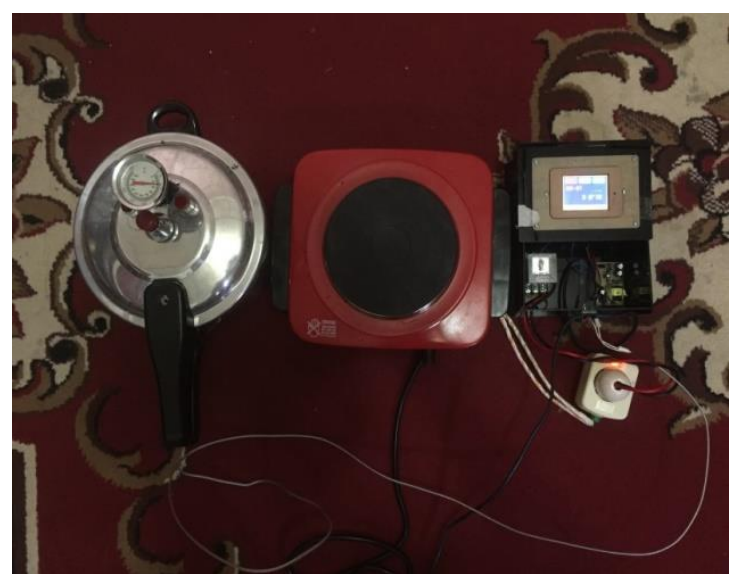

Gamabr 11. Bentuk Alat Keseluruhan

A. Peralatan dan bahan pengujian.

1. MUlTimeter

Merek : Sanwa

2. TOOL SET

Merek : Cadik - Elektronika

Tipe : ESSEN

\section{B. Pengujian Hardware}

1. Pengujian LCD

Pada rangkaian LCD dilakukan pengujian terhadap Keluaran yang teorinya sebesar $10 \mathrm{~V}$ setelah dilakukan pengujian maka didapatkan :

Tabel 1. Hasil Pengukuran Tegangan LCD

\begin{tabular}{cccc}
\hline No & Posisi Sensor & Teori & Hasil Pengukuran \\
\hline 1 & ON & $10 \mathrm{~V}$ & $9 \mathrm{~V}$ \\
\hline 2 & OFF & $0 \mathrm{~V}$ & $0 \mathrm{~V}$ \\
\hline
\end{tabular}

Analisa :

Dari hasil penelitian terhadap fungsi dari LCD, maka dapat di berikan penjelasan bahwa LCD bekerja dengan baik sebelum sistem dijalankan. Pada saat alat Sistem Sterilisator Otomatis Berbasis Arduino Uno dijalankan 
nilai dari tampilan awal LCD akan berubah sesuai dengan pengukuran yang dilakukan oleh sensor suhu dan timer.

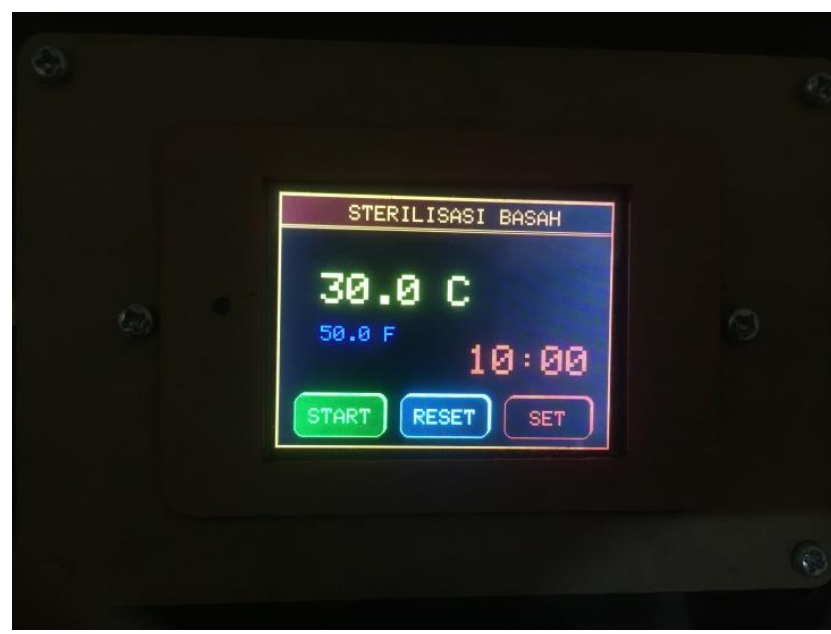

Gambar 12. Tampilan LCD

2. Pengujian Heater

Pengujian Heater dilakukan untuk dapat mengetahui bekerja atau tidaknya heater pada saat alat Sistem Sterilisator Otomatis Berbasis Arduino Uno di jalankan. Heater pada alat yang penulis buat ini berfungsi sebagai element pemanas untuk memanaskan air sampai suhu dan waktu yang kita inginkan tercapai. Pada pengujian heater maka didapatkan :

Tabel 2. Hasil Pengukuran Tegangan Heater

\begin{tabular}{cccc}
\hline No & Posisi Saklar & Teori & Hasil Pengukuran \\
\hline 1 & ON & $220 \mathrm{~V}$ & $210 \mathrm{~V}$ \\
\hline 2 & OFF & $0 \mathrm{~V}$ & $0 \mathrm{~V}$ \\
\hline
\end{tabular}

Analisa :

Dari hasil penelitian terhadap heater, maka dapat di berikan penjelasan bahwa heater bekerja dengan baik. Pada saat alat Sistem Sterilisator Otomatis Berbasis Arduino Uno dijalankan maka Heater akan ON / bekerja secara otomatis. Heater akan terus $O N$ / bekerja sampai suhu dan waktu yang di setting sebelumnya telah tercapai.

\section{Pengujian Output Switching Power Supply}

Pengujian Output Switching Power Supply bertujuan untuk dapat mengetahui apakah masukan yang diberikan Switching power supply ke seluruh rangkaian sistem berjalan dengan baik sesuai dengan teori dasarnya. Pada pengujian ini teori dasar dari Switching power supply mempunyai masukan sebesar $12 \mathrm{~V}$, dan setelah penulis melakukan pengukuran penulis mendapatkan hasil Output Switching power supply yaitu sebesar $10 \mathrm{~V}$. setelah dilakukan pengujian didapatkan hasil:

Tabe 3. Hasil Pengujian Output Switching Power Supply

\begin{tabular}{cccc}
\hline No & Posisi Saklar & Teori & Hasil Pengukuran \\
\hline 1 & ON & $12 \mathrm{~V}$ & $10 \mathrm{~V}$ \\
\hline 2 & OFF & $0 \mathrm{~V}$ & $0 \mathrm{~V}$ \\
\hline
\end{tabular}

Analisa :

Dari hasil penelitian terhadap fungsi Switching Power Supply, maka dapat di berikan penjelasan bahwa Switching Power Supply bekerja dengan baik. jika Switching Power Supply tidak bekerja dengan baik atau outputnya tidak ada maka alat Sistem Sterilisator Otomatis Berbasis Arduino Uno tidak akan dapat dijalankan, karena pada pembuatan Tugas Akhir ini Switching Power Supply merupakan salah satu komponen utama yang berfungsi memberikan arus dan tegangan ke komponen lainnya.

4. Pengujian sensor suhu

Pengujian sensor suhu ini dilakukan dengan menghubungkan sensor suhu dengan Arduino agar dapat bekerja dengan baik. Sensor suhu yang penulis gunakan pada alat ini yaitu sensor suhu jenis Thermocouple. Dengan menghubungkan sensor suhu dan LCD ke Arduino dapat mengatur kerja sensor suhu sesuai dengan program yang dibuat oleh penulis. Thermocouple dihubungkan ke modul rangkaian thermocouple yang terhubung ke kaki 11, 12, 13 Arduino uno. Setelah dilakukan pengujian maka didapatkan hasil: 
Tabel 4. Pengujian Sensor Suhu

\begin{tabular}{cccc}
\hline NO & Posisi Saklar & Teori & Hasil Pengukuran \\
\hline 1 & ON & $5 \mathrm{~V}$ & $4,8 \mathrm{~V}$ \\
\hline 2 & OFF & $0 \mathrm{~V}$ & $0 \mathrm{~V}$ \\
\hline
\end{tabular}

Analisa :

Dari hasil penelitian terhadap fungsi sensor suhu, maka dapat di berikan penjelasan bahwa sensor suhu bekerja dengan baik. Pada saat alat Sistem Sterilisator Otomatis Berbasis Arduino Uno dijalankan maka sensor suhu mulai mendeteksi suhu samapai suhu yang disetting telah tercapai. Penulis juga membandingkan hasil kerja dari sensor suhu yang ditampilkan pada LCD alat ini dengan thermometer dan hasil pengukuran suhunya sama dengan sensor suhu yang ada pada alat penulis ini.

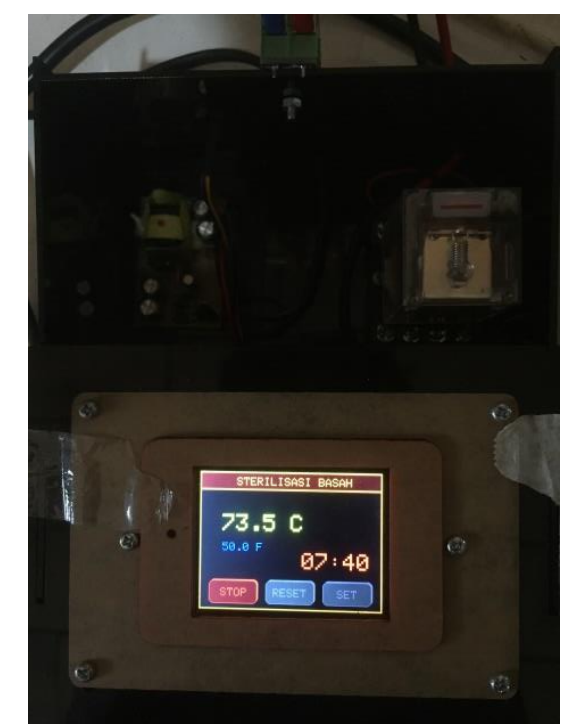

Gambar 13. Pengujian fungsi sensor suhu

\section{Pengujian Buzzer}

Pada alat yang penulis buat ini menggunakan buzzer yang berfungsi sebagai penanda pada saat suhu dan waktu sterilisasi telah tercapai. Buzzer nantinya akan mengeluarkan suara pada saat suhu yang sebelumnya telah diseting telah tercapai. Dari hasil pengujian buzzer penulis mendapatkan hasil seperi yang dapat dilihat pada gambar dan tabel berikut ini.
Tabel 5. Pengukuran Buzzer

\begin{tabular}{cccc}
\hline `NO & Posisi Saklar & Teori & Hasil Pengukuran \\
\hline 1 & ON & $5 \mathrm{~V}$ & $4,8 \mathrm{~V}$ \\
\hline 2 & OFF & $0 \mathrm{~V}$ & $0 \mathrm{~V}$ \\
\hline
\end{tabular}

Analisa :

Dari hasil penelitian terhadap fungsi buzzer, maka dapat di berikan penjelasan bahwa buzzer bekerja dengan baik. Pada saat alat Sistem Sterilisator Otomatis Berbasis Arduino Uno dijalankan maka sensor suhu mulai mendeteksi suhu sampai suhu yang disetting telah tercapai maka buzzer akan langsung aktif dan mengeluarkan suara atau $O N$ menandakan suhu yang diinginkan telah tercapai, dan waktu akan menghitung mundur untuk proses sterilisasinya dan pada saat waktu menunjukkan 00 maka Buzzer akan langsung aktif kembali dan mengeluarkan suara atau $O N$ tanpa ada delay sebagai tanda bahwa proses sterilisasi telah selesai dilakukan.

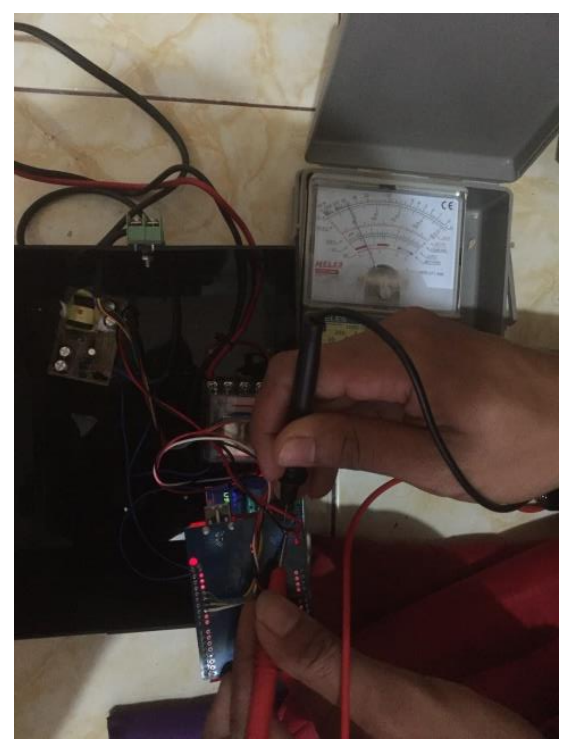

Gambar 14. Pengujian buzzer

\section{Pengujian Software}

1. Program konfigurasi pin arduino Berikut list programnya :

\#define relaypin 10

\#define buzzerPin A5

MAX6675 thermocouple1 (13, 12, 11) ; // (thermoCLK, thermoCs, thermoDo) \#define YP A3 
\#define XM A2

\#define YM 9

\#define XP 8

TouchScreen ts $=$ TouchScreen $(X P, Y P, X M$, YM, 300);

Adafruit TFTLCD tft(A3, A2, A1, A0, A4); $/ /($ LCD_CS, LCD_CD, LCD_WR, LCD_RD, LCD_RE $\bar{S} E T)$;

\section{Program tampilan LCD}

\section{Berikut list programnya}

\#include <SPFD5408 Adafruit TFTLCD.h>

\#include <SPFD5408 TouchScreen.h>

\#include <EEPROM.h>

\#define YP A3

\#define XM A2

\#define YM 9

\#define XP 8

Touchscreen ts $=$ TouchScreen $(\mathrm{XP}, \mathrm{YP}, \mathrm{XM}$, YM, 300) :

Adafruit TFTLCD tft(A3, A2, A1, A0, A4);

/ / (LCD_CS, LCD_CD, LCD_WR, LCD_RD, LCD RESET);

\#de $\bar{f}$ ine BLACK

\#define RED

$0 \times 0000$

tefine

$0 \times F 800 / / F^{*}$

\#define D_RED 0x7800

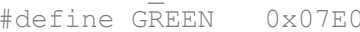

\#define M GREEN 0x05e0

\#define D_GREEN 0x0400

\#define BLUE 0x001F

\#define M BLUE 0x0019

\#define D ${ }^{-}$BLUE $0 \times 0012$

\#define PINK OxF81F

\#define M_PINK 0xB817

\#define D PINK 0x680d

\#define CȲAN $0 \times 07 \mathrm{FF}$

\#define M_CYAN Ox0574

\#define D CYAN 0x03ae

\#define YËLLOW OxFFE0//0xF800 0x07E0

\#define M YELLOW Oxce20

\#define D YELLOW 0x8c40

\#define L_GREY OxC618

\#define M GREY OX8410

\#define D GREY 0x52aa

\#define GOLLD OxFE60

\#define M GOLD Oxee00

\#define D GOLD 0xac60

\#define BT̄OSCA 0x04bf

\#define M BTOSCA 0x0356

\#define D_BTOSCA 0x01ed

\#define GTOSCA 0x07f6

\#define M GTOSCA 0x0651

\#define D_GTOSCA 0x044C

\#define ORANGE OxFDOC

\#define BROWN OxcCOO

\#define M BROWN 0x8ac0

\#define D BROWN 0x59e0

\#define LIME Ox07E0

\#define WHITE OxFFFF

\#define GOLD OXFEAO

\#define NAVY 0x000F

\#define MAROON 0x7800

byte width $=0$;

byte height $=0$;

void setup()

\{

tft.reset ()

tft.begin(tft.readID()) ;

Serial.begin (9600);

tft.height ();

tft.width ();
tft.setRotation (3) ;

tft.fillscreen (BLACK) ;

mainframe ();

showButton (jumlahTombol) ;

void loop () \{

tombol (jumlahTombol);

void print2digits (int number)

if (number $>=0$ \&\& number $<10$ )

//Serial.write('0');

tft.print ("0") ;

tft.print (number)

//Serial.print (number)

void printLcd(uint16 t $x$, uint16 t y,

uint16 t ukuran, uint16 t warna,

uint16_t warnaLatar, str̄ing teks)

tft. setCursor ( $x, y)$;

tft.setTextSize (ukuran)

tft.setTextColor (warna, warnaLatar);

tft.print (teks);

void mainframe()

tft.fillscreen (BLACK) ;

tft.fillRect $\left(0,0,379,32, D_{-}\right.$RED) ;

garisDatar (0, GOLD)

garisDatar (2, GOLD);

tulis $(65,10,2$, GOLD, D_RED,

"STERILISASI BASAH")

garisDatar(30, GOLD) ;

garisDatar (32, GOLD) ;

$1 /============$
$/ /$ Design Interface ( 1 ines)

tft.fillRect $(0,0$, 320, 2, GOLD) ;//atas

tft.fillRect (0, 238, 320, 2, GOLD);//bwh

tft.fillRect $(0,0,2,240$, GOLD) ;//kiri

tft.fillRect $(318,0,2,240$,

GOLD) ; / / kanan

void settingFrame () \&

tft.fillscreen (BLACK);

tft.fillRect (0, 0, 379, 32, D RED);

garisDatar (0, GOLD);

garisDatar (2, GOLD) ;

tulis $(65,10,2$, GOLD, D RED, "SETTING

PARAMETER")

garisDatar (30, GOLD)

garisDatar (32, GOLD) ;

$/ /============$

printLcd (120, 45, 2, GOLD, BLACK, "") ;

tft.print ("SUHU ") ;

printLcd $(100,100,4$, YELLOW, BLACK,

") ;

if $($ setTemp $<100)$

tft.print ("0"); //tft.print (" C")

tft.print (setTemp); tft.print (" C");

\} else \{

tft.print (setTemp); tft.print (" C");

\}

if ( setst $==2) \quad\{$

printLcd (120, 45, 2, GOLD, BLACK, "") ;

tft.print ("WAKTU") ;

printLcd(100, 100, 4, YELLOW, BLACK,

" ")

if (setTimer $<10)$ \{

tft.print ("O"); //tft.print (" C");

tft.print (setTimer); tft.print ("

mnt") ;

\} else \{ 


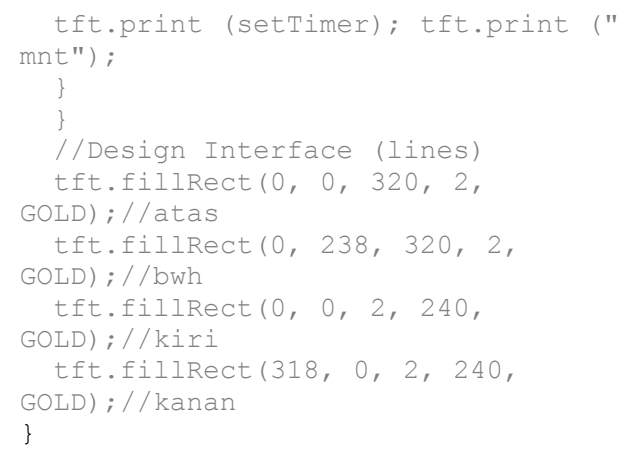

3. Program sensor suhu

Berikut list programnya :

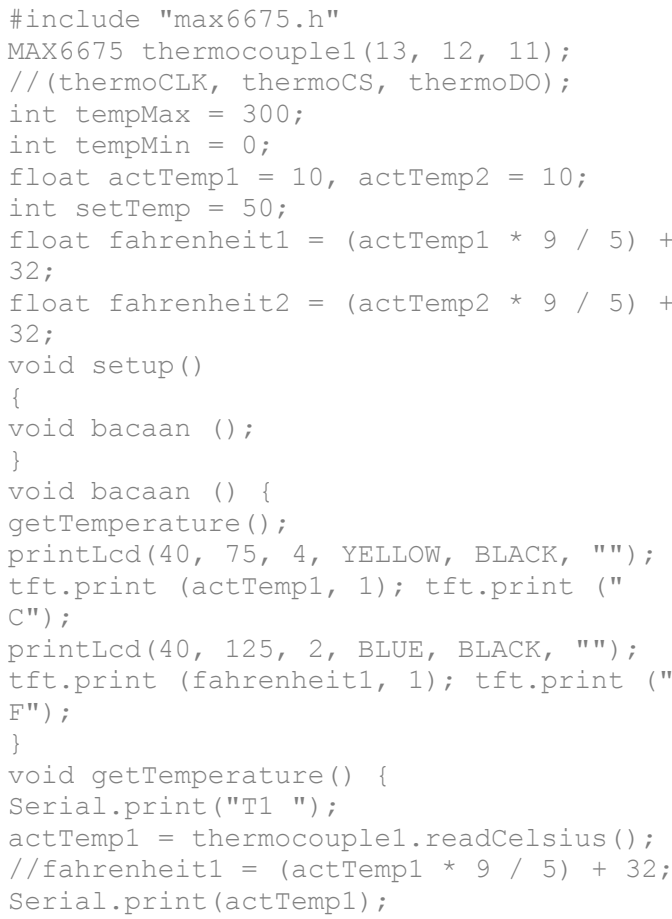

4. Program Relay dan Buzzer

Berikut list programnya :

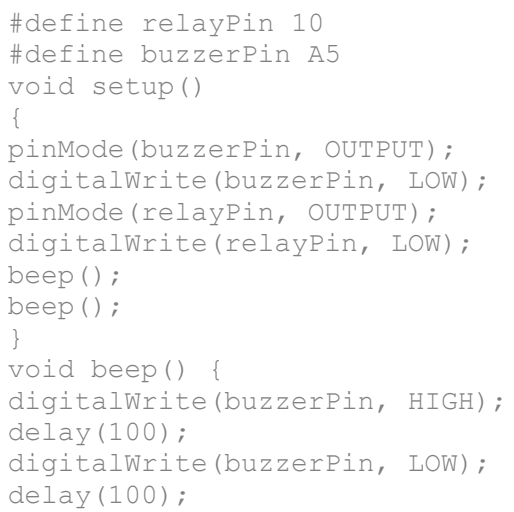

\section{Pengujian Alat secara keseluruhan}

Adapun tujuan pengujian ini yaitu untuk melihat sejauh mana hasil dan kerja alat sistem Sterilisasi Otomatis Berbasis Arduino Uno, sehingga didapat hasil dan perbandingan dari apa yang direncanakan sebelumnya. Pada tahap ini, alat akan dioperasikan secara normal dengan menghubungkan ke kontak listrik. Pengujian alat secara keseluruhan dapat dilihat pada tabel berikut.

Berikut langkah-langkah pengujian alat yang tealah dibuat :

1. Persiapkan gunting atau pinset medis sebagai alat yang akan disterilkan sebagai media penelitian.

2. Hubungkan box kontroler ke sumber listrik.

3. Hubungkan heater ke sumber listrik.

4. Hubungkan heater ke box kontroler.

5. Isi wadah penampung dengan air bersih secukupnya dan letakkan ke heater.

6. Atur suhu dan waktu yang dinginkan pada tampilan LCD.

7. Tekan tombol Start.

Tabel 6. Pengujian alat keseluruhan

\begin{tabular}{cccccc}
\hline No & $\begin{array}{c}\text { Media yang } \\
\text { disterilkan }\end{array}$ & Waktu & Suhu & Relay & $\begin{array}{c}\text { Keadaan } \\
\text { Alat }\end{array}$ \\
\hline 1 & Pinset & $\begin{array}{c}0 \\
\text { menit }\end{array}$ & $0^{\circ} \mathrm{C}$ & Off & Kotor \\
\hline 2 & Pinset & $\begin{array}{c}10 \\
\text { Menit }\end{array}$ & $120^{\circ} \mathrm{C}$ & On & Bersih \\
\hline
\end{tabular}

\section{Penutup}

Berdasarkan hasil pengujian terhadap pembuatan alat Sistem Sterilisator Otomatis Berbasis Arduino Uno, maka diperoleh kesimpulan alat ini berjalan dengan sangat baik, dimulai dari keadaan media sterilisasi yang kotor menjadi bersih. Kesimpulan ini penulis dapatkan bukan dari pengujian dengan alat ukur pada media yang disterilkan tetapi dari teori-teori dan penelitian yang telah banyak dilakukan oleh para ahli yang mengatakan bahwa spora bakteri baru dan kuman akan mati pada suhu diatas $80{ }^{\circ} \mathrm{C}$. Dari segi keefektifan waktu alat ini juga memiliki segi keefektifan waktu yang cukup akurat ini dibuktikan dalam pengujian alat ini waktu yang di inputkan 10 menit untuk mencapai suhu $120^{\circ} \mathrm{C}$ dan hasilnya sesuai dengan teori yaitu dalam waktu 10 menit suhu yang dikeluarkan sebesar $120^{\circ} \mathrm{C}$. 


\section{REFERENSI}

[1] M. Maryani and T. Cahyono, "Studi Efektifitas Desinfeksi Dan Sterilisasi Dalam Menurunkan Angka Kuman Alat Set Medikasi Di Rumah Sakit Wijayakusuma Purwokerto Tahun 2015," Bul. Keslingmas, vol. 35, no. 1, pp. 79-81, 2016, doi: 10.31983/keslingmas.v35i1.3081.

[2] P. Rahardjo, J. T. Elektro, F. Teknik, and U. Udayana, "Sistem Pengendali Temperatur Untuk Proses Pasteurisasi Alat-alat Medis Temperature Controller System," vol. 9, no. 1, 2010.

[3] M. Mikrobiologi, A. Satria, and R. Agustini, "Makalah Mikrobiologi 'Sterilisasi,"' pp. 1-19.

[4] N. Saputera and R. Hidayatullah, "Rancang Bangun Alat Sterilisasi Kesehatan," Politek. Negeri Banjarmasin, vol. 5662, no. November, pp. 20-34, 2018.

[5] P. S. Teknik, T. Udara, J. Teknik, M. Politeknik, and N. Bali, "Pemanfaatan Energi Panas Terbuang pada Kondensor AC Sentral Jenis Water Chiller untuk Pemanas Air Hemat Energi I Made Rasta Wasted Heat Engine Utilization in Central AC Condenser Type Water Chiller for Economical Energy Water Heaters," vol. 3, no. 2, pp. 114-120, 2009.

[6] D. Sutarya, A. Unjuk, K. Thermocouple, and W. P. Suhu, "Analisis Unjuk Kerja Thermocouple W3Re25," no. 01, 2008.

[7] Septiari Ugi Purwitasari, Priyambada Cahya N, and Tri Bowo Indrato, "Modifikasi Sterilisator Basah Dilengkapi Dengan Pengisian Dan Pengosongan Air Otomatis,"

[8] Saputera, N., Nurkamalia, N., Zuraidah, Z and Qamariah, Q, "Rancang Bangun Alat Sterilisasi Kesehatan Berbasissmart Relay Zelio SR2 B121JD," In Seminar Nasional Riset Terapan (Vol. 3, pp. C20-C34), 2018.

[9] Maryani M, and Cahyono, T, "Studi Efektifitas Desinfeksi Dan Sterilisasi Dalam Menurunkan Angka Kuman Alat Set Medikasi Di Rumah Sakit Wijayakusuma Purwokerto Tahun 2015," Buletin Keslingmas, 35(1), 79-81, 2016.

[10] H. Wiworo, H. Siti and H. B Maria, "Panci Tekan Sebagai Alat Sterilisasi Alternatif Pengganti Autoklaf," Poltekkes Kemenkes Yogyakarta, 2019.

\section{Biodata Penulis}

M. Aditya, lahir di Simalanggang, 27 Maret 1998. Menyelesaikan studi DIV Teknik Elektro Industri pada Jurusan Teknik Elektro Fakultas Teknik Universitas Negeri Padang.

Dwiprima Elvanny Myori, S.Si, M.Si, lahir di Palembang, 01 November 1988. Menyelesaikan studi S1 Matematika di Universitas Andalas pada tahun 2010. Pendidikan S2 Matematika di Universitas Andalas pada tahun 2012. Saat ini terdaftar sebagai dosen tetap di jurusan Teknik Elektro Fakultas Teknik Universitas Negeri Padang. 